\title{
Gestão estratégica da qualidade aplicada à redução de devoluções
}

\section{Strategic quality management applied to reducing returns}

\author{
Pedro Vieira Souza Santos Engenheiro de Produção. Universidade Federal do Vale do São Francisco (UNIVASF) - Brasil. \\ pedrovieirass@hotmail.com \\ Eduína Carla da Silva Engenheira de Produção. Universidade Federal de Campina Grande (UFCG) - Brasil. \\ eduinac@gmail.com.
}

\begin{abstract}
RESUMO
A ineficiência das operações traduz-se como desperdício de recursos que podem gerar custos e resultados abaixo do almejado. Nesse contexto, as devoluções são resultantes, na maioria dos casos, por falha nas operações do processo. $O$ presente artigo caracteriza-se como um estudo de caso, onde a coleta de dados foi possível por meio de acesso aos relatórios fornecidos pela organização, onde pôde-se identificar os registros históricos do indicador de devolução. Neste artigo foi possível aplicar as principais ferramentas da qualidade para tentar reduzir os níveis de devoluções em uma empresa de distribuição de produtos alimentícios. Foram analisados dados referentes ao período do primeiro e segundo trimestre deste ano, ou seja, de janeiro a março em comparação com dados de abril a junho de 2018. Isto posto, a aplicação destas justificou-se pela ampla difusão em ações de gestão, auxiliando na melhoria dos serviços e processos locais. Pôde-se perceber que as ferramentas podem facilitar a definição, mensuração, análise e ainda proposta de soluções e/ou alternativas à resolução de gargalos que influenciam o desempenho da empresa, impactando em diversos aspectos, como financeiro e operacional.
\end{abstract}

Palavras-chave: Retorno de produtos. Gestão da qualidade. Ferramentas gerenciais.

\section{ABSTRACT}

Inefficiency of the operations translates as waste of resources that can generate costs and results below the target. In this context, returns are the result, in most cases, of a failure in process operations. In this article it was possible to apply the main quality tools to try to reduce the levels of returns in a food distribution company. Data for the first and second quarter of this year were analyzed, that is, from January to March, compared to data from April to June 2018. The application of these tools was therefore justified by the wide diffusion in management actions, improvement of local services and processes. It can be noticed that the tools can facilitate the definition, measurement, analysis and also propose solutions and / or alternatives to solve bottlenecks that influence the performance of the company, impacting in several aspects, such as financial and operational.

Keywords: Return of products. Quality management. Management tools.

Recebido em 27/12/2018. Aprovado em 13/02/2019. Avaliado pelo sistema double blind peer review. Publicado conforme normas da ABNT. http://dx.doi.org/10.22279/navus.2019.v9n4.p30-49.884 


\section{INTRODUÇÃO}

A competitividade presente nos mercados atuais tem fomentado o desenvolvimento de políticas de gestão que tornem os processos internos às empresas mais eficientes. Assim, a ineficiência das operações traduz-se como desperdício de recursos que podem gerar custos e resultados abaixo do almejado. Um aspecto que pode ser associado a este fato é a ocorrência de devoluções de produtos comercializados pela organização no mercado que atua (SHEN; LI, 2015; SANTOS; SANTOS, 2018).

O retorno de mercadorias pode ser estimulado por diversos motivos, entre eles, os mais comuns são relacionados à qualidade do produto e a política de vendas local (LI; XU; LI, 2013). Para Xu et al. (2015), o contexto no qual a empresa está inserida determinará como a organização se comportará diante dos registros de devolução, considerando o ciclo de vida do produto, o impacto das devoluções na receita empresarial e prazos de entrega aceitáveis e definidos com os clientes. Assim, a estratégia para minimizar os índices de retorno pode ser implementada com base em uma análise mais detalhada do problema.

Considerando que as devoluções representam problemas para qualquer organização, estas podem ser reduzidas a partir da utilização de ferramentas gerenciais que garantam a qualidade do processo e assim tornem as operações mais produtivas (KUMAR; SOLEIMANI; GOVINDAN, 2014). Por meio dessas ferramentas, a gestão torna-se capaz de aumentar o controle em relação aos processos locais, identificando pontos críticos e estabelecendo prioridades na resolução dos problemas existentes.

Para Neyestani (2017) e Santos e Araújo (2018) as ferramentas da qualidade possuem papel primordial quando se objetiva melhorar o desempenho em uma organização, podendo monitorar, obter, analisar dados para detectar e resolver os problemas dos processos de produção, a fim de facilitar a obtenção de excelência nas operações como um todo. Dale, Dehe e Bamford (2016) citam ainda que o emprego dessas técnicas é direcionado para uma abordagem de solução de problemas para máxima eficácia e eficiência da organização.

Logo, o presente trabalho, reforça a importância do desenvolvimento do tema de gestão estratégica da qualidade no contexto investigado, isto é, no ramo de serviços. A partir do estudo de caso aqui desenvolvido, tem-se a possibilidade de verificar como a administração estratégica influencia na qualidade das operações, rumo à obtenção de vantagem competitiva.

Santos et al. (2017) apontam essa necessidade de gerir a organização de forma estratégica, argumentando que: "a partir dos acontecimentos do mundo globalizado e pela evolução da tecnologia, observa-se a necessidade constante dos empreendimentos buscarem atualizações em relação aos conceitos de gestão e inovação para, com isso, se adequarem aos novos cenários que surgem a todo o momento." Assim, alcançar a qualidade do serviço e a satisfação do cliente é necessário para obter rentabilidade e vantagem competitiva em qualquer setor (ALFALAH, 2017).

Em concordância com a afirmativa anterior, Fujun, Xiaolin e Vincent (2009) consideram que a qualidade do serviço prestado deve ser parte substancial da empresa, importante para consolidar a satisfação do cliente. Portanto, o objetivo deste estudo é aplicar ferramentas da qualidade para redução do índice de devolução em uma empresa distribuidora de alimentos localizada na cidade de Juazeiro-BA.

\section{ABORDAGEM TEÓRICA}

Nesta seção, pretende-se discutir, do ponto de vista teórico, as devoluções e seus desdobramentos no contexto organizacional, com enfoque na área de gestão da qualidade.

\subsection{Devoluções}

Uma das ocasiões em que o ciclo de venda do produto não é completado é a existência de devoluções de produtos. Nesse caso, tem-se o fato de que, por alguma razão, o produto não foi recebido pelo consumidor final, retornando ao ciclo produtivo (ACOSTA;WEGNER; PADULA, 2008). Quando registrada a devolução, o "[...] objetivo estratégico é agregar valor ao produto devolvido" (LEITE, 2006, p. 17). 
Trata-se de uma forma de canal de distribuição reverso da pós-venda (GUARNIERI et al., 2006). Isto posto, os retornos de mercadorias acabam originando um tipo de logística denominada reversa onde, após volta do produto ao local de venda, há possibilidade de remanufatura. Para Leite e Brito (2005, p. 2018), podese caracterizar esta situação "[...] quando o produto retornado ou os seus componentes apresentam condições de serem reparados ou reelaborados parcialmente de forma a adquirir condições de venda em mercados secundários."

Nesse cenário, pode-se entender que os retornos de produtos comercializados são considerados como limitadores de rendimento para os lucros de qualquer empresa. Portanto, analisar as causas dos retornos e compreender os impactos destes para a organização deve ser uma prática gerencial comum. Como consequência, a gestão poderá iniciar o tratamento de retornos, a partir da determinação de um nível de devolução aceitável (HJORT, 2013). Para cumprir esta atividade, é imprescindível a implementação de uma gestão da qualidade.

\subsection{Gestão da qualidade}

O conceito do termo "qualidade" tem uma ampla variedade. Para alguns, a qualidade está associada ao significado de superioridade e excelência, e para outros a qualidade é uma garantia de que há menos serviços ou produtos com defeitos. Por outro lado, o termo está ligado às características do produto (ALZHRANI;ALOTIBIE; ABDULAZIZ, 2016). Contudo, salienta-se que a maioria das definições focam nos clientes e sua satisfação (TAKALO et al., 2013; SANTOS, 2018).

A abordagem acerca do tema gestão da qualidade pode ser citada com o início da operação de inspeção em meados de 1900. Logo na década de 1930, a análise por meio de métodos estatísticos e o controle de qualidade foram desenvolvidos e entraram em cena no contexto industrial. Mais tarde, em torno de 1950 os chamados gurus da qualidade revolucionaram a área, com difusão do método consolidado de gestão da qualidade (SCHROEDER; GOLDSTEIN; RUNGTUSANATHAM, 2013). Atualmente, a função qualidade é vista como uma área mais ampla, sendo traduzida como uma abordagem integrada para alcançar e sustentar resultados de alta qualidade que envolve todos os níveis gerenciais.

Embora a gestão da qualidade tenha sido definida de várias maneiras, sob diferentes abordagens, um fato é comum em relação a todas elas, o foco no cliente, com melhoria contínua e apoio a tomada de decisões (HELLSTEN; KLEFSJÖ, 2000). Nesse sentido, a gestão da qualidade deve ser vista como um conjunto de práticas e/ou técnicas de gestão direcionados a toda a empresa, objetivando fornecer produtos e/ou serviços que atendam aos requisitos exigidos pelos clientes em termos de expectativa e funcionalidade (MOLINA-AZORÍN et al., 2009).

Na ótica de Yeung, Cheng e Lai (2005), as práticas ligadas à gestão da qualidade, em geral, retratam um conjunto bem definido e integrado de processos operacionais com base na qualidade de entrega, ou seja, características de um produto ou serviço que satisfazem uma necessidade determinada pelos clientes. Ademais, Agus (2005) cita que diversas obras encontradas na literatura associam ainda a gestão da qualidade com desempenho local, onde, segundo Pu, Su e Liu (2011) o uso efetivo do gerenciamento da qualidade pode afetar significativamente o mesmo. Pimentel e Major (2014) citam que a gestão da qualidade contribui para a mudança organizacional e também no desempenho financeiro da empresa.

\subsection{Ferramentas da qualidade}

Para Dale, Dehe e Bamford (2016) para dar apoio, desenvolver e ainda promover um processo de melhoria contínua na organização e seus processos internos, é necessário que a mesma use uma gama de opções de ferramentas e técnicas dispostas para este objetivo. Brow et al. (2006, p. 274) declaram que é de extrema importância "[...] estar ciente de que as ferramentas e técnicas da qualidade desempenham um papel importante na qualidade estratégica".

De acordo com a literatura, há diversas ferramentas que dão suporte e/ou são direcionadas para a gestão da qualidade em organizações. Segundo Kerzner (2009) as sete ferramentas básicas de controle da 
qualidade são: folha de verificação, fluxograma, histograma, gráfico de Pareto, diagrama de causa e efeito, diagrama de dispersão e carta de controle.

1. Diagrama de Pareto: esta ferramenta organiza itens de acordo com a magnitude da contribuição destes, identificando produtos que possuem maior influência. Isto é, ordena as frequências das ocorrências, da maior para a menor. É amplamente utilizada para priorizar projetos de melhoria e corrigir problemas, apontando por exemplo, produtos com maior devolução, reclamações mais registradas e outros. O princípio de Pareto é conhecido como regra $80 / 20$, o que significa que $80 \%$ dos problemas são ocasionados por $20 \%$ das causas (MAGAR; SHINDE, 2014).

2. Diagrama de causa e efeito: trata-se de uma ferramenta que mostra a relação de forma sistemática entre o problema identificado e as possíveis causas (CARPINETTI, 2012). É capaz de gerar, de modo eficiente, ideias sobre as possíveis causas de problemas correntes e apresentar de forma estruturada. Ainda conhecida como Diagrama de Ishikawa e/ou Diagrama de Espinha de Peixe, pode ser considerada, em suma, uma ferramenta da qualidade que auxilia a levantar as causas-raízes de um problema (CARVALHO et al., 2012). Para Simanová e Gejdoš (2015, p. 279) “[...] O diagrama é em forma de espinha de peixe e o eixo principal é a gestão da qualidade."

3. Histograma: são gráficos de barras que mostram o padrão de distribuição das observações, agrupando-as em intervalos de classe e dispostos em ordem de grandeza. São úteis no estudo de padrões de distribuição e/ou ainda a avaliação da normalidade de um conjunto de dados (MIOT, 2017). O histograma, de acordo com Cooper e Schindler (2003) é uma solução convencional para apresentação de dados de intervalo e de razão.

Segundo Simanová e Gejdoš (2015, p. 279):

A base de blocos individuais (no eixo $\mathrm{x}$ ) corresponde à largura do intervalo, e a altura dos blocos (no eixo y) expressa a frequência das variáveis da variável monitorada em intervalos apropriados. Na gestão da qualidade, refere-se principalmente à distribuição de frequência de valores de qualidade ou valores relacionados a fatores de produção que influenciam a qualidade dos produtos. (SIMANOVÁ; GEJDOŠ, 2015, p. 279).

4. Gráfico de dispersão: ferramenta que se baseia na necessidade de se conhecer o relacionamento entre duas variáveis (MAGAR; SHINDE, 2014), tendo em vista que um relacionamento pode ou pode não existir entre as variáveis observadas. Quando existentes, estas podem ser positiva ou negativa, forte ou fraca e pode ser ainda simples ou complexa. De acordo com Reis e Reis (2002), esta consiste basicamente em traçar uma série de pontos representando várias observações em um gráfico em que uma variável está no eixo $X$ e a outra variável no eixo $\mathrm{Y}$.

5. Cartas de controle: foram criadas por Walter A. Shewhart nos anos 20, dão uma visão gráfica do comportamento do processo ao longo do tempo (PINTO, 2007); ainda são empregadas para determinar quando o processo está em controle. Este tipo de ferramenta possibilita uma atuação de forma preventiva, por meio da visualização de possíveis soluções para o problema, mantendo o produto sob controle (LACHMAN; LIEBERMAN; KANIG, 2001); assim, impedem que o problema ocorra efetivamente.

Uma outra característica desse tipo de gráfico é que desempenham um papel importante na aceitação do produto em análise, pois através do controle estatístico verifica-se a estabilidade e a homogeneidade do produto ou serviço (SANTOS et al., 2010). Carvalho et al. (2012, p. 374) afirma ainda que "esta ferramenta introduziu as bases quantitativas para a avaliação da qualidade e marcou o uso da estatística como instrumento básico da avaliação da qualidade em nível de processos."

6. Fluxograma: capaz de representar visualmente e de forma organizada, as etapas sequenciais do processo local, a partir da utilização de símbolos que representam os diferentes tipos de operações. Segundo Forbes e Ahmed (2011) ainda é muito útil para encontrar e melhorar a qualidade no processo. Um fluxograma é uma representação diagramática de um algoritmo. Kuruvila et al. (2017) cita que esta ferramenta consiste em várias formas gráficas, como círculo, retângulo, paralelogramo e outras, que são conectadas usando linhas de conexão. Cada forma corresponde a uma operação específica e apontada por um texto. 
7. Folha de verificação: na visão de Carpinetti (2012), esta ferramenta é utilizada, com grande eficiência, para o planejamento e para a coleta de dados, simplificando e organizando-a. Para Corrêa e Corrêa (2012, p. 205), a folha de verificação tem como objetivo "[...] garantir que o ganho obtido pela aplicação das seis anteriores, não seja perdido ou esquecido depois que os problemas, já resolvidos, deixarem de ocupar as atenções da operação". Além disso, as folhas de verificação ajudam o usuário a organizar os dados para a utilização posterior (MONTGOMERY, 2009).

\section{METODOLOGIA}

O presente artigo caracteriza-se como um estudo de caso. Gil (2002) cita que o estudo de caso tem como intuito explorar situações do cotidiano para explicar as variáveis causais de determinado fenômeno em diversas situações. Yin (2003) e Cauchick-Miguel (2007), complementam ao afirmarem que trabalhos desse tipo se comportam como investigadores de informações teóricas em suas atividades práticas, podendo assim permitir a comprovação e confronto da revisão da literatura com a realidade.

O estudo desenvolvido apresenta-se ainda como uma pesquisa exploratória, que de acordo com Gil $(2002$, p.41) tem a finalidade de "proporcionar maior familiaridade com o problema, com vistas a torná-lo mais explícito ou a constituir hipóteses". Como forma de embasamento teórico, foi executada uma pesquisa bibliográfica, justificando-se por colocar o pesquisador em contato com o que já se produziu a respeito do tema de pesquisa. Visa desvendar, recolher e analisar as principais contribuições sobre um determinado assunto (PÁDUA, 2004).

Logo, a coleta de dados foi possível por meio de acesso aos relatórios fornecidos pela organização, onde pôde-se identificar os registros históricos do indicador de devolução. Foram analisados dados referentes ao período do primeiro e segundo trimestre deste ano, ou seja, de janeiro a março em comparação com dados de abril a junho de 2018.

\subsection{Das etapas do estudo}

A sequência de etapas na qual a pesquisa se deu foi:

a. Reunião para apresentação da proposta de estudo: nesta primeira etapa, pôde-se discutir a possibilidade de intervenção no processo local a fim de apresentar melhorias aplicando as ferramentas da qualidade.

b. Estipulação dos objetivos da pesquisa: foi-se acordado que o indicador de devolução seria viável para estudo, tendo em vista o grau de importância que a gestão da empresa aloca no mesmo, fazendo parte da estratégia local reduzi-lo ao máximo.

c. Coleta de dados: no primeiro momento foram coletados por meio de relatórios gerenciais fornecidos pelo sistema eletrônico da empresa e, a partir destes arquivos, teve-se a oportunidade de observar o comportamento dos indicadores ao longo dos seis meses (dois trimestres).

d. Aplicação das ferramentas da qualidade: nesta fase da pesquisa, foram definidas e aplicadas pela equipe de trabalho do setor (com apoio dos pesquisadores) as principais ferramentas da qualidade mais utilizadas e citadas na literatura e que oferecessem respostas as questões postas sobre devolução de produtos. Isto é, Diagrama de Pareto, Fluxograma, Plano de ação, Diagrama de causa e efeito e estratificação.

e. Construção do plano de ação - $5 \mathrm{~W} 1 \mathrm{H}$ : trata-se de uma ferramenta amplamente empregada em situações deste tipo. Esta permite a gestão local traçar ações relevantes que acarretarão no atendimento dos requisitos para tornar a devolução menos comum, isto é, com níveis menores de ocorrência.

f. Avaliação: foi-se definida uma verificação em forma de avaliação dos resultados nos meses posteriores aos dois primeiros trimestres até o fim do corrente ano. Para isto, será observada a consolidação do índice de devolução mensal abaixo da meta estipulada. Como o resultado desta etapa será observado futuramente, o mesmo não pôde ser descrito no presente artigo. 


\section{RESULTADOS E DISCUSSÃO}

Nesta seção, serão apresentados os resultados obtidos no estudo, evidenciando o cenário inicial encontrado, as aplicações de ferramentas da qualidade e as melhorias alcançadas e identificadas.

\subsection{Identificação do cenário inicial}

A princípio, ressalta-se que, o nome da empresa estudada não será apontado nesse estudo. Tal fato se dá a partir da premissa de discrição solicitada pela empresa. Como trata-se de dados estratégicos, o estudo compromete-se em apontar de forma clara a aplicação das ferramentas da qualidade no contexto empresarial selecionado, ou seja, no ramo de serviços. A escolha dessa empresa, se deu com base na facilidade de acesso para coleta de dados, mas, sobretudo, pela necessidade apontada pela alta administração em rever o processo de administração estratégica, derivando em objetivos de desempenho que garantam a melhor execução das operações.

Como base para início da discussão, é importante ressaltar a definição de devolução para a empresa em estudo. Como trata-se de uma distribuidora de alimentos, as vendas são registradas em aparelhos eletrônicos dos vendedores. Estes profissionais são designados para atender os estabelecimentos por área, isto é, são alocados por conjunto de bairros da cidade. Quando a venda é feita, as informações sobre a mesma são repassadas eletronicamente no final do dia para o sistema da empresa, que emite ordem de separação de pedidos para entrega no dia útil seguinte.

Logo, os pedidos recebidos são separados e carregados nos veículos da empresa. A organização conta com oito caminhões para este serviço. Na saída dos veículos na portaria da empresa é feita uma verificação da quantidade de caixas na carga versus o volume. Este momento, tem grande importância, pois no retorno da equipe de entrega, será possível fazer o cálculo do que realmente foi entregue com o que saiu para entregar nos clientes. Assim, o índice de devolução é determinado pela razão entre volume carregado/vendido e volume retornado, dado em porcentagem (\%). É importante ressaltar que a empresa em estudo não possui um valor determinado para índice de devolução aceitável, ou seja, uma meta de retorno diária/mensal para acompanhamento, apenas é feito o registro destes. Tal fato será comentado posteriormente nesta sessão.

Portanto, tendo em vista a necessidade de registrar os dados do período que compreende o primeiro trimestre de 2018 (janeiro a março), foram extraídos do sistema eletrônico de registro de dados (SERD) da empresa os valores do índice de devolução para o período, sendo estes apresentados no Gráfico 01.

Gráfico 01 - Registro do índice de devolução no $1^{\circ}$ trimestre de 2018

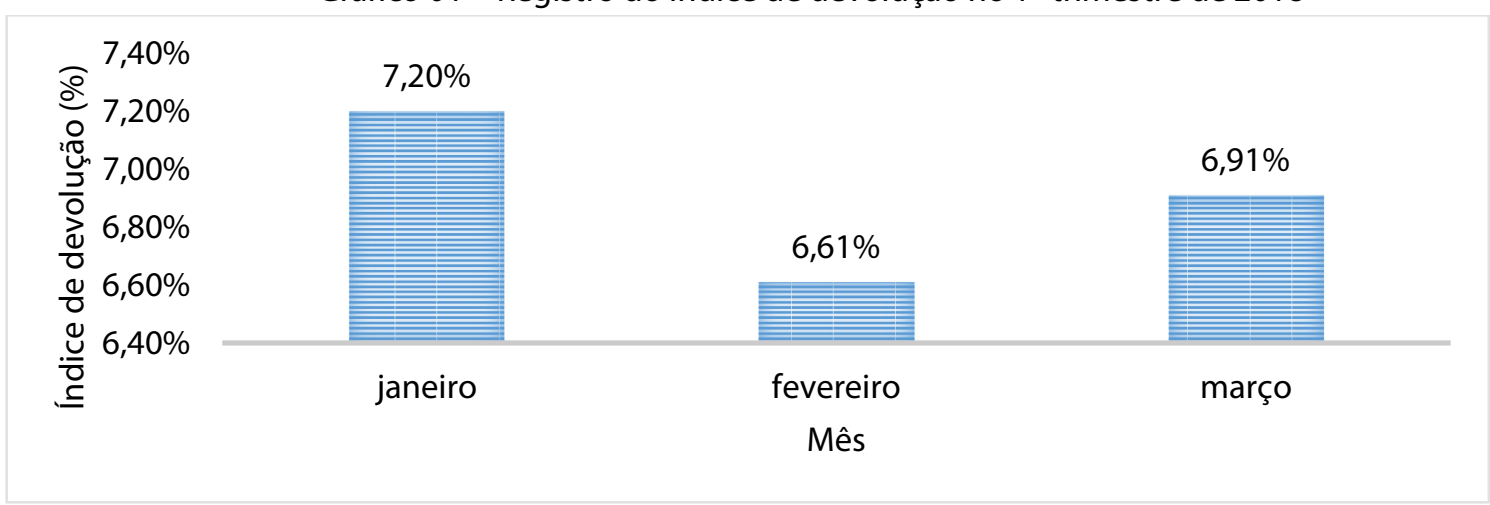

Fonte: Dados da empresa (2018).

Como observado, dos meses iniciais do ano de 2018, janeiro registrou maior número de devoluções, com $7,20 \%$ do total de vendas realizadas no mês, seguido por março com 6,91\% e fevereiro com registro de 
6,61\%. A empresa possui uma lista de motivos de devolução, construída com base nas principais razões de retorno registradas. Para este período, de janeiro a março, os principais motivos de devolução, em ordem de maior ocorrência, são apresentados na Tabela 01.

Tabela 01 - Principais motivos de devolução no $1^{\circ}$ trimestre de 2018
Motivo
No

\section{registrado}

\begin{tabular}{lcc}
\hline Estabelecimento Fechado & 67 & $45 \%$ \\
Cancelamento do pedido & 22 & $15 \%$ \\
Cliente sem dinheiro & 21 & $14 \%$ \\
Produto/Quantidade errada & 15 & $10 \%$ \\
Forma de pagamento divergente & 13 & $9 \%$ \\
Não fez pedido & 8 & $5 \%$ \\
Outros & 4 & $3 \%$ \\
\hline Total & 146 & $100 \%$ \\
\hline
\end{tabular}

Fonte: Dados da empresa (2018).

Das 6 principais razões, pode-se notar que o motivo estabelecimento fechado é o mais comum registrado no período, com 67 devoluções, representando 46\% do total no trimestre. Outra observação importante a se fazer é que os dois primeiros motivos representam mais de $50 \%$ das ocorrências totais de devolução, ou seja, $60 \%$ destas são impactadas por estabelecimento fechado e cancelamento do pedido.

Em termos de impacto financeiro, a organização repassou os valores correspondentes a cada devolução registrada efetivamente, ou seja, uma estimativa do valor que não foi arrecadado em detrimento das devoluções. Os dados referentes a estes valores são apresentados na Tabela 02.

Tabela 02 - Impacto das devoluções em termos financeiros

Mês Quantidade de Impacto financeiro

devoluções

\begin{tabular}{ccc}
\hline Janeiro & 61 & $-\mathrm{R} \$ 5.870,66$ \\
Fevereiro & 34 & $-\mathrm{R} \$ 3.520,17$ \\
Março & 55 & $-\mathrm{R} \$ 5.013,02$ \\
\hline
\end{tabular}

Fonte: Dados da empresa (2018).

Como os meses de janeiro e março registraram maior número efetivo de devoluções, estes, consequentemente, apresentam-se como meses com maior impacto financeiro registrado pela empresa. Para a organização, estes valores englobam o custo com os processos internos, como pessoal, tecnologia, materiais e outros, além do valor dispendido na operação de entrega. Não foi possível averiguar a memória de cálculo destas informações, pois esta não é o foco do trabalho, servindo apenas para conhecimento e complemento da discussão do artigo. 


\subsection{Aplicação das ferramentas da qualidade}

Após a identificação do cenário local, com observação dos dados inerentes à devolução de mercadorias na empresa, as ferramentas da qualidade foram aplicadas com o intuito de entender os altos índices de devolução e tentar minimizá-los nos períodos seguintes, mantendo-os em patamar estável.

Com isso, foi utilizado no primeiro momento o fluxograma, representado pela Figura 01, para entender as etapas sequenciais do processo, desde a chegada no cliente ao ato de devolução. Este foi construído de acordo com informações extraídas do setor de entrega no qual não havia ainda utilizado esta ferramenta para visualização do processo.

Figura 01 - Fluxograma do processo de entrega e devolução

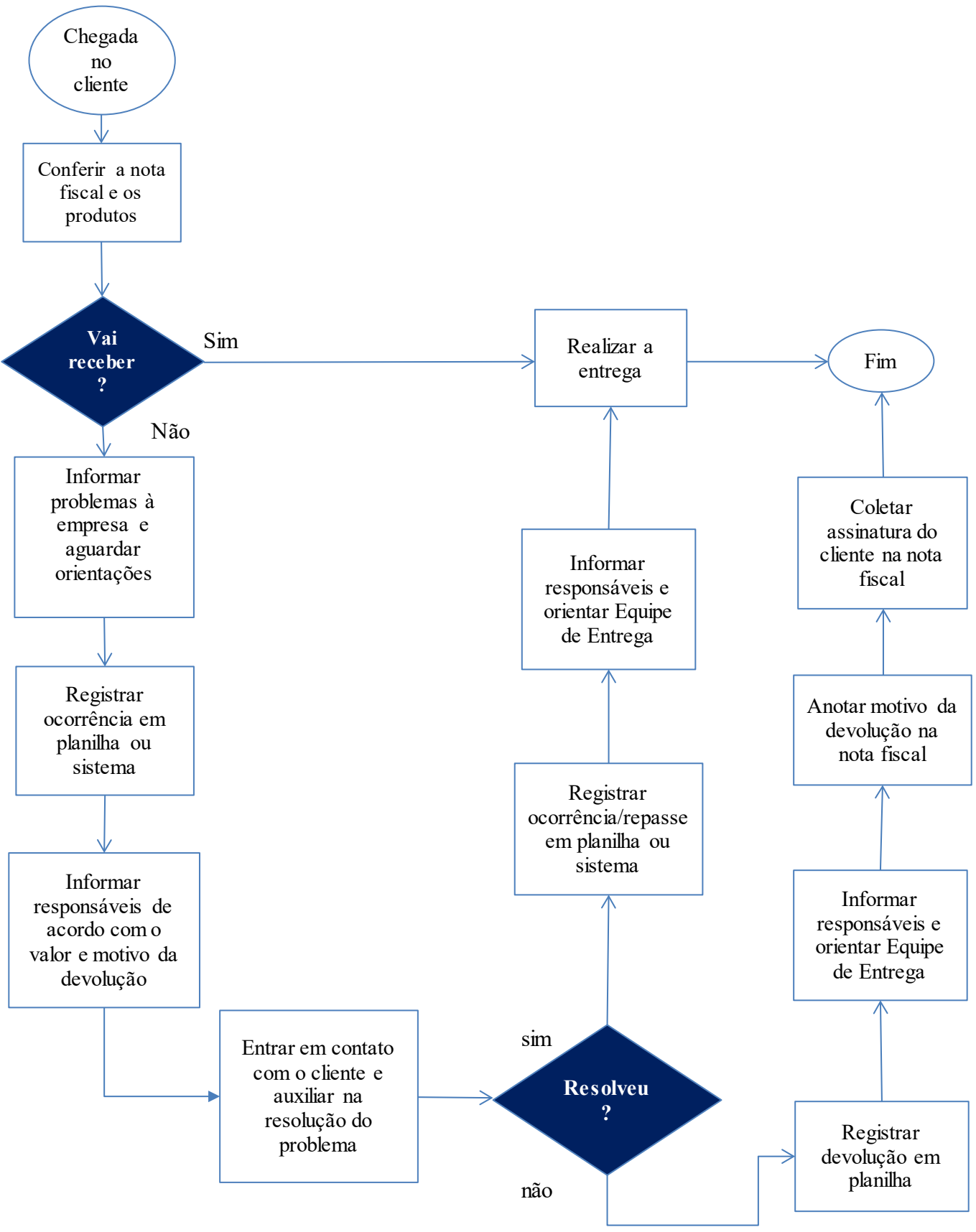

Fonte: Autoria própria (2018). 
Este fluxograma foi elaborado tendo em vista o objetivo de mostrar de maneira descomplicada o fluxo das informações, além da sequência de operações que caracteriza o trabalho que está sendo executado na empresa. Este será usado em momentos futuros para treinamento das equipes de trabalho responsáveis pela operação. Isto é, serão enfatizados os procedimentos técnicos necessários à padronização do processo de entrega, com foco na resolução de devoluções, facilitando assim, o entendimento dos colaboradores para com as etapas essenciais ao processo.

Com a sequência de atividades construída, outra ferramenta da qualidade foi utilizada com o intuito de analisar os principais aspectos de devolução registrados no trimestre. O histograma (Figura 02) foi elaborado com dados do sistema da empresa e mostra a frequência na qual as devoluções ocorrem por dia da semana entre as equipes da sede (região central) e interior.

Figura 02 - Histograma acerca dos registros diários de devolução no $1^{\circ}$ trimestre 2018

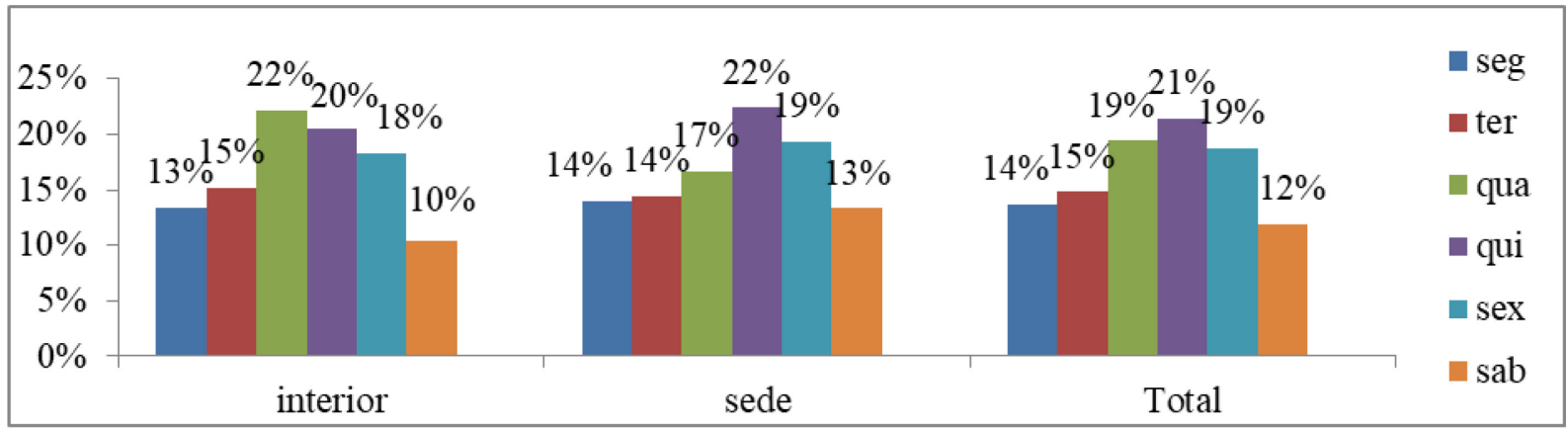

Fonte: Autoria própria (2018).

Como pode-se notar, a maioria das ocorrências é feita na quarta (interior) e na quinta-feira para região central. A partir desta ferramenta, dados foram obtidos por medições periódicas, ou seja, nos indicam um panorama dos padrões que mais se repetiram nesse período referente ao primeiro trimestre de 2018 . Em seguida, foi feito um Diagrama de Pareto, representado no Gráfico 02.

Gráfico 02 - Diagrama de Pareto para motivos de devolução

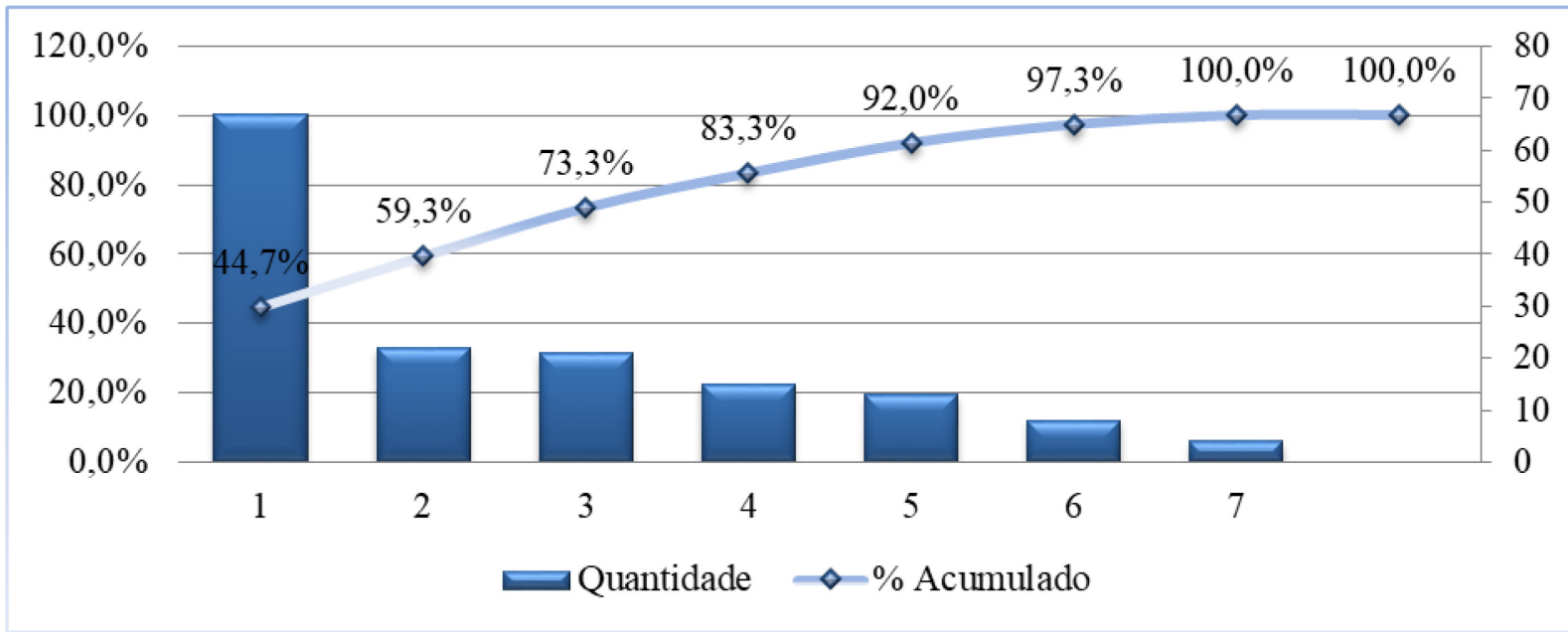

Fonte: Autoria própria (2018).

Para construção do Diagrama de Pareto foram utilizados os dados contidos na Tabela 03. 
Tabela 03 - Dados para construção do Diagrama de Pareto

\begin{tabular}{clccc} 
Item & \multicolumn{1}{c}{ Defeito/Problema } & Quantidade & $\%$ & $\%$ Acumulado \\
\hline $\mathbf{1}$ & Estabelecimento Fechado & 67 & $44,7 \%$ & $44,7 \%$ \\
$\mathbf{2}$ & Cancelamento do pedido & 22 & $14,7 \%$ & $59,3 \%$ \\
$\mathbf{3}$ & Cliente sem dinheiro & 21 & $14,0 \%$ & $73,3 \%$ \\
$\mathbf{4}$ & Produto/Quantidade errada & 15 & $10,0 \%$ & $83,3 \%$ \\
$\mathbf{5}$ & Forma de pagamento divergente & 13 & $8,7 \%$ & $92,0 \%$ \\
$\mathbf{6}$ & Não fez pedido & 8 & $5,3 \%$ & $97,3 \%$ \\
$\mathbf{7}$ & Outros & 4 & $2,7 \%$ & $100,0 \%$ \\
\hline & Total & 150 & $100 \%$ & $100 \%$ \\
\hline
\end{tabular}

Fonte: Autoria própria (2018).

Como percebido pelo Diagrama de Pareto, os motivos "Estabelecimento Fechado", "Cancelamento do pedido", "Cliente sem dinheiro" e "Produto/quantidade errada" representam aproximadamente $80 \%$ dos registros de produtos devolvidos. A partir do Diagrama pode-se observar a distribuição dos itens relacionados a devolução, organizando-os do mais frequente ao menos frequente. A sua utilização neste trabalho é de suma importância, pois será utilizado para definir as prioridades a serem tomadas para ação pela empresa. Além disso, representa um passo inicial para determinar os esforços iniciais a serem feitos para obter um resultado positivo máximo.

Portanto, os problemas referentes aos itens em destaque no Gráfico 02 serão tratados de forma prioritária por este estudo, tendo em vista seu impacto para organização. Para aprofundar as análises foi feito um Diagrama de causa e efeito, representado na Figura 03, para o motivo 1, ou seja, de devolução por Estabelecimento fechado. Vale a pena salientar que esta ferramenta é utilizada neste artigo para descobrir as possíveis causas do problema de devolução. Além disso, esta permite que a equipe de gestão local identifique, explore e apresente graficamente, em mais detalhes, todas as possíveis causas relacionadas ao problema de retorno de mercadoria ou ainda pode ser uma condição para descobrir sua (s) causa (s).

Figura 03 - Diagrama de causa e efeito para devoluções motivo 1

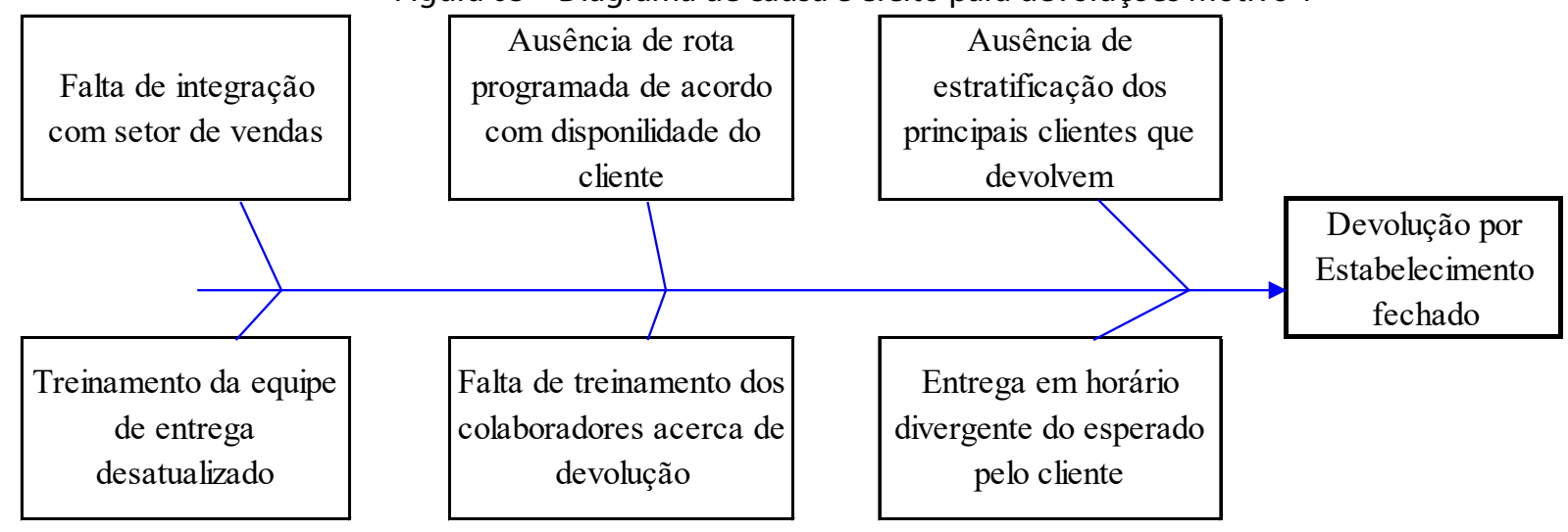

Fonte: Autoria própria (2018).

Para construção deste diagrama, foi feita uma reunião com a equipe gestora local para citarem as causas que podem impactar no efeito de devolução por motivo de devolução por estabelecimento fechado. $\mathrm{O}$ efeito aqui estudado foi identificado previamente e a análise do diagrama construído facilitará a percepção das potenciais causas através de uma visão sistêmica e que foi integrada por diversos pontos de 
vista. Assim, foi feito na sequência, um Diagrama de causa e efeito, representado na Figura 04, para o motivo 2, ou seja, de devolução por Cancelamento do pedido.

Figura 04 - Diagrama de causa e efeito para devoluções motivo 2

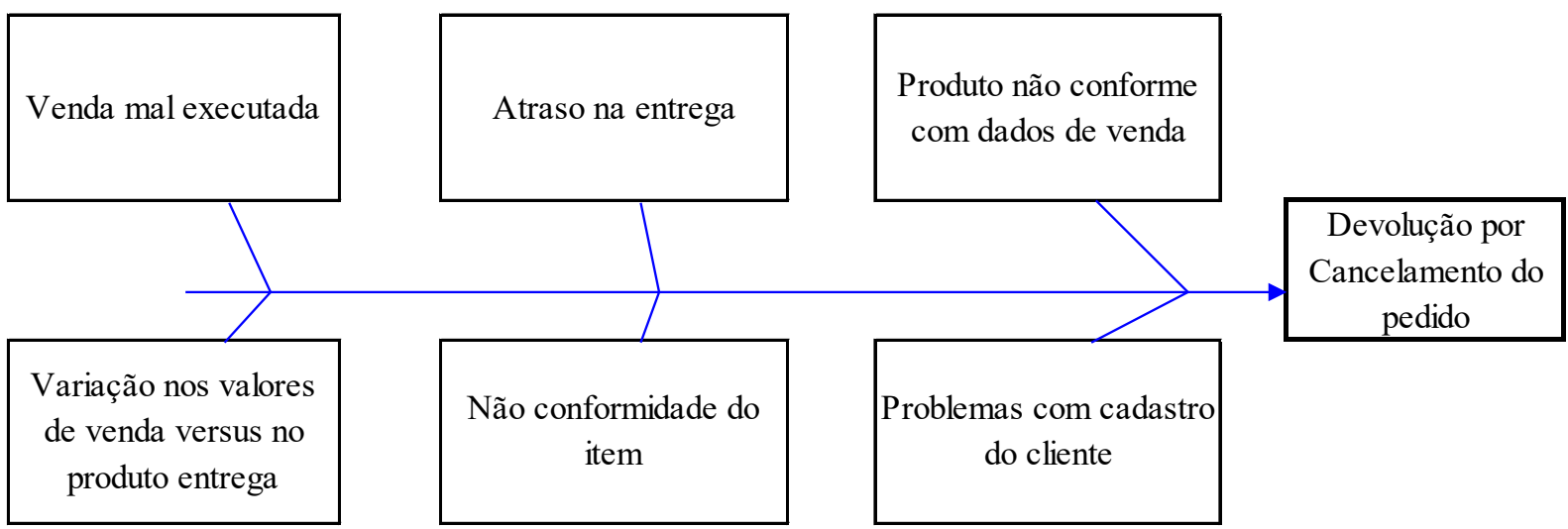

Fonte: Autoria própria (2018).

A integração entre setores para identificação de causas é essencial, principalmente em uma organização como a estudada, onde as ações do setor de vendas impactam diretamente na distribuição e devem ser integradas com o setor de entrega para que não haja divergência nas informações e as operações possam ser bem executadas. Nesse sentido, dando continuidade a abordagem da ferramenta de causa e efeito, foi elaborado um Diagrama de causa e efeito, representado na Figura 05, para o motivo 3, ou seja, de devolução por Cliente sem dinheiro.

Figura 05 - Diagrama de causa e efeito para devoluções motivo 3

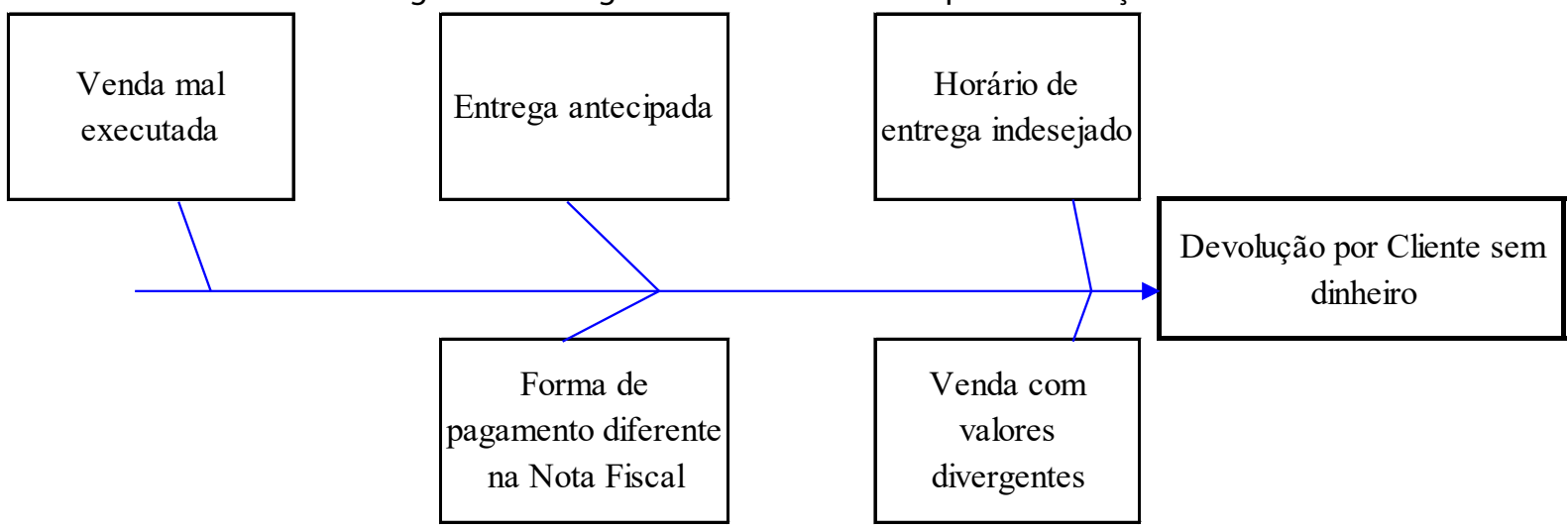

Fonte: Autoria própria (2018).

Dando continuidade as causas ligadas as devoluções com motivos de maior impacto em termos de quantidade, foi montado Diagrama de causa e efeito (Figura 06), para o motivo 4, isto é, retorno por Produto/Quantidade errada. 
Figura 06 - Diagrama de causa e efeito para devoluções motivo 4

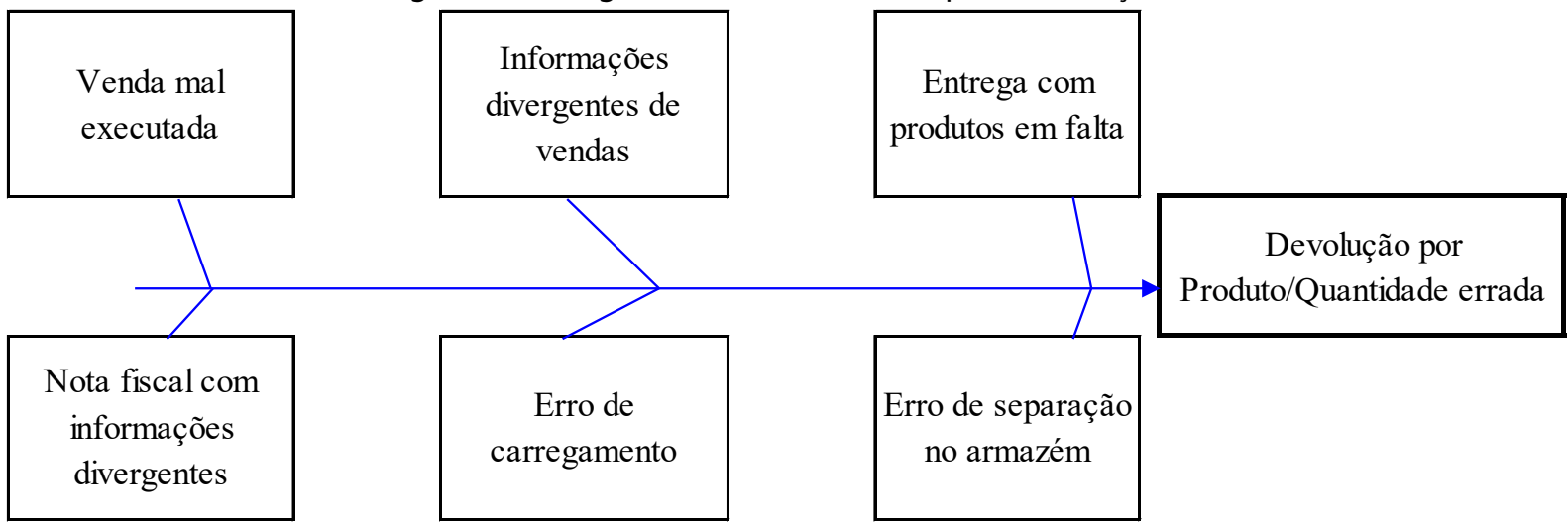

Fonte: Autoria própria (2018).

A partir da construção dos diagramas acima foi possível traçar ações que deverão minimizar a ocorrência de devoluções devido aos quatro principais motivos identificados. Assim, foi traçado um plano de ação, conforme Quadro 01, para organizar as medidas que serão postas em prática para cumprir este objetivo.

\begin{tabular}{|c|c|c|c|c|c|}
\hline O quê (What) & Por quê (Why) & $\begin{array}{c}\text { Onde } \\
\text { (Where) }\end{array}$ & Quem (Who) & Quando (When) & Como (How) \\
\hline $\begin{array}{l}\text { Treinamento da } \\
\text { equipe acerca de } \\
\text { devoluções }\end{array}$ & $\begin{array}{c}\text { Para explicar os } \\
\text { impactos de uma } \\
\text { devolução para a } \\
\text { empresa }\end{array}$ & Empresa & Gestão local & Em até 30 dias & $\begin{array}{l}\text { Através de } \\
\text { palestras e } \\
\text { campanhas } \\
\text { internas de } \\
\text { divulgação }\end{array}$ \\
\hline $\begin{array}{l}\text { Integração entre } \\
\text { setores }\end{array}$ & $\begin{array}{l}\text { Compartilhamento } \\
\text { de informações } \\
\text { acerca de vendas e } \\
\text { entrega }\end{array}$ & Empresa & Direção & Imediatamente & $\begin{array}{c}\text { Estabelecer } \\
\text { Acordo de Nível } \\
\text { de Serviço }\end{array}$ \\
\hline $\begin{array}{l}\text { Implementação } \\
\text { de sistema de } \\
\text { roteirização } \\
\text { informatizado }\end{array}$ & $\begin{array}{c}\text { Melhorar } \\
\text { distribuição dos } \\
\text { veículos }\end{array}$ & Empresa & Direção & Em até 60 dias & $\begin{array}{l}\text { Emprego de } \\
\text { software } \\
\text { comercial para } \\
\text { este fim }\end{array}$ \\
\hline $\begin{array}{l}\text { Estratificar } \\
\text { principais } \\
\text { clientes que } \\
\text { devolvem }\end{array}$ & $\begin{array}{l}\text { Identificar clientes } \\
\text { críticos para o } \\
\text { processo }\end{array}$ & Empresa & Gestão local & Em até 30 dias & $\begin{array}{l}\text { A partir de } \\
\text { dados do } \\
\text { sistema } \\
\text { eletrônico } \\
\text { interno }\end{array}$ \\
\hline $\begin{array}{l}\text { Atualizar } \\
\text { cadastros de } \\
\text { clientes }\end{array}$ & $\begin{array}{l}\text { Padronizar horário } \\
\text { de entrega por } \\
\text { cliente e atualizar } \\
\text { forma de } \\
\text { pagamento } \\
\text { desejada }\end{array}$ & Empresa & Gestão local & Em até 10 dias & $\begin{array}{l}\text { A partir de } \\
\text { dados do } \\
\text { sistema } \\
\text { eletrônico } \\
\text { interno }\end{array}$ \\
\hline
\end{tabular}




\begin{tabular}{|c|c|c|c|c|c|}
\hline $\begin{array}{l}\text { Reciclagem de } \\
\text { treinamento do } \\
\text { time de vendas }\end{array}$ & $\begin{array}{c}\text { Diminuir devoluções } \\
\text { por motivos de } \\
\text { vendas }\end{array}$ & Empresa & Direção & Em até 30 dias & $\begin{array}{l}\text { Através de } \\
\text { palestras e } \\
\text { capacitações }\end{array}$ \\
\hline $\begin{array}{c}\text { Analisar } \\
\text { viabilidade de } \\
\text { entrega no } \\
\text { sábado }\end{array}$ & $\begin{array}{c}\text { Reduzir devoluções } \\
\text { por motivo de } \\
\text { mercado }\end{array}$ & Empresa & Direção & Em até 60 dias & $\begin{array}{l}\text { Demonstração e } \\
\text { comparação de } \\
\text { custos por } \\
\text { entrega por } \\
\text { equipe }\end{array}$ \\
\hline $\begin{array}{l}\text { Criar padrão } \\
\text { operacional para } \\
\text { carregamento }\end{array}$ & $\begin{array}{l}\text { Evitar erros de } \\
\text { carregamento }\end{array}$ & Empresa & Gestão local & Em até 20 dias & $\begin{array}{c}\text { Reunir } \\
\text { informações } \\
\text { como fluxo, } \\
\text { responsabilidad } \\
\text { es e outras } \\
\text { acerca da } \\
\text { operação }\end{array}$ \\
\hline $\begin{array}{l}\text { Criar padrão } \\
\text { operacional para } \\
\text { separação de } \\
\text { pedidos }\end{array}$ & $\begin{array}{c}\text { Evitar erros por } \\
\text { separação de itens }\end{array}$ & Empresa & Gestão local & Em até 20 dias & $\begin{array}{c}\text { Reunir } \\
\text { informações } \\
\text { como fluxo, } \\
\text { responsabilidad } \\
\text { es e outras } \\
\text { acerca da } \\
\text { operação }\end{array}$ \\
\hline $\begin{array}{l}\text { Definir meta de } \\
\text { devolução } \\
\text { mensal/diária }\end{array}$ & $\begin{array}{l}\text { Parametrizar o } \\
\text { indicador }\end{array}$ & Empresa & Gestão local & Em até 10 dias & $\begin{array}{l}\text { Verificar limite } \\
\text { tolerável }\end{array}$ \\
\hline
\end{tabular}

Fonte: Autoria própria (2018).

Portanto, a partir da utilização do plano de ação acima elaborado foi possível definir as principais ações que contribuirão para atingimento do objetivo estipulado neste trabalho, pois trata-se de um documento que permite fazer o planejamento sistemático do trabalho necessário para alcançar o resultado.

\subsection{Dos resultados obtidos}

A princípio, das ações definidas, vale ressaltar uma que poderá ajudar a empresa a acompanhar melhor o indicador. Trata-se da definição de meta diária de devolução, assim, a partir de reuniões e estudos acerca do índice e seu registro histórico na empresa, foi acordado que a meta para retornos seria de $5 \%$ ao dia e/ou 5\% ao mês. Este valor poderá ser recalculado em momentos posteriores para atualização de acordo com evolução do indicador nos próximos meses. Logo, após execução de boa parte do plano de ação acima citado no mês de abril, pôde-se perceber melhoras nos índices de devolução registrados nos meses seguintes, de maio e junho de 2018, conforme visualizado na Tabela 04. 
Tabela 04 - Principais motivos de devolução em maio e junho de 2018

Motivo

No registrado

(\%)

\begin{tabular}{lcc}
\hline Estabelecimento Fechado & 37 & $40 \%$ \\
Cancelamento do pedido & 17 & $18 \%$ \\
Cliente sem dinheiro & 11 & $12 \%$ \\
Produto/Quantidade errada & 12 & $13 \%$ \\
Forma de pagamento divergente & 9 & $10 \%$ \\
Não fez pedido & 2 & $2 \%$ \\
Outros & 5 & $5 \%$ \\
\hline Total & 93 & $100 \%$ \\
\hline
\end{tabular}

Fonte: Dados da empresa (2018).

O motivo estabelecimento fechado continua sendo o maior em termos de ocorrência. De acordo com a organização, apesar da quantidade estar diminuindo, como observado em comparação com o primeiro trimestre do ano, a mesma espera conseguir controlar ainda mais este motivo de devolução. Para a gestão, trata-se de uma questão de tempo, até que todos os estabelecimentos cadastrados no sistema, cerca de 874 unidades, possam ser revisados em relação a cadastro geral, observando o horário de entrega mais adequado para eles, assim como identificação de necessidades especiais.

Em relação ao impacto financeiro, a empresa pôde calcular os valores associados a devolução nesses dois meses, ou seja, uma estimativa do quantitativo que não foi arrecadado por causa das devoluções. Os dados referentes a estes valores são apresentados na Tabela 05.

Tabela 05 - Impacto das devoluções em termos financeiros

\begin{tabular}{ccc} 
Mês & Quantidade de devoluções & Impacto financeiro \\
& & \\
\hline Maio & 45 & $-\mathrm{R} \$ 3.521,00$ \\
Junho & 48 & $-\mathrm{R} \$ 4.248,10$ \\
\hline
\end{tabular}

Fonte: Dados da empresa (2018).

Apesar dos altos valores ainda registrados, a empresa espera continuar em ritmo de redução das devoluções com o melhoramento das operações e execução de ações nas diversas áreas. Apesar dos retornos representarem um impacto no cenário negativo nas arrecadações, a administração já pôde notar significativo redução nas perdas financeiras. Logo, pode ser observado no Gráfico 03, que o índice de devolução nos meses após a aplicação das ferramentas da qualidade foi menor do que os meses anteriores, antes da implementação da gestão da qualidade. 
Gráfico 03 - Registro do índice de devolução no $1^{\circ}$ semestre de 2018

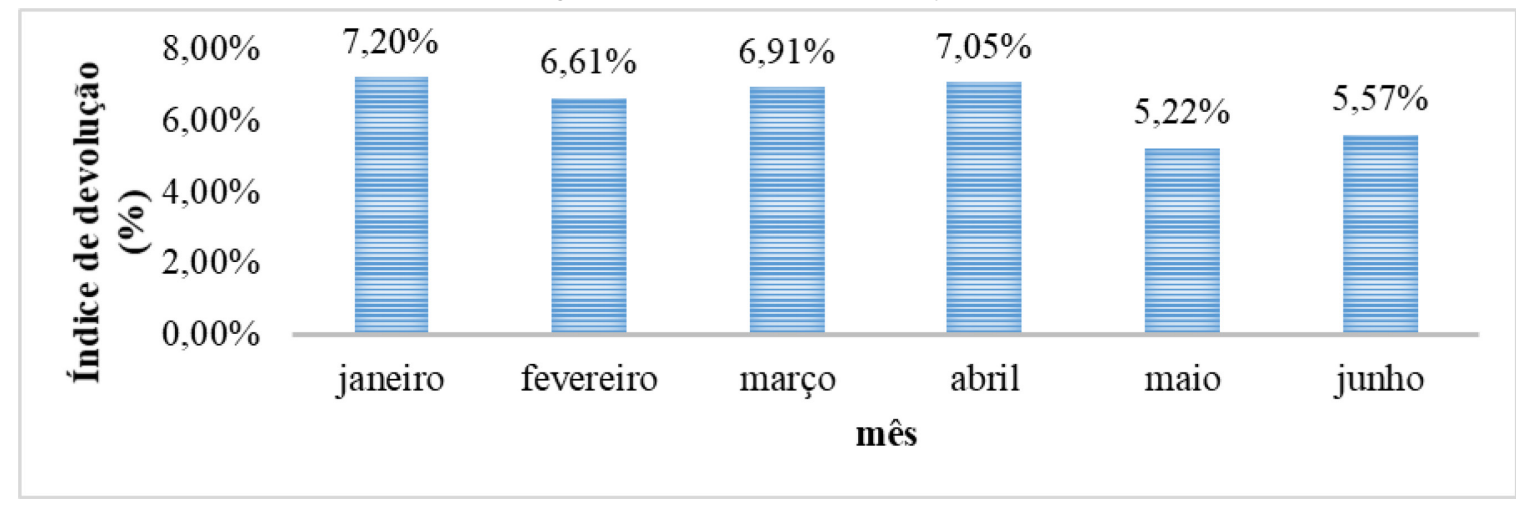

Fonte: Dados da empresa (2018).

Vale salientar que o mês de abril não foi impactado pela pesquisa, tendo em vista que este foi o mês no qual a gestão local implementou as ações definidas pelo plano de ação com base nas ferramentas da qualidade. Contudo, é notório que houve uma queda de aproximadamente $2 \%$ no indicador nos meses seguintes, ou seja, de maio e junho em comparação a abril. A alta no mês de junho em relação a maio se deu devido ao alto volume comercializado neste mês. Isto posto, quanto maior o número de vendas, mais chance de haver uma devolução de produto.

\subsection{Outras medidas}

Além dessas ações, onde a maioria pôde ser executada e outras ainda estão em fase de implementação e/ou desenvolvimento, outras ações foram indicadas para que o processo seja monitorado com mais eficiência. Logo, cita-se como principais ações a serem pensadas pela gestão local:

- Implementação de carta de controle para acompanhar devoluções hora a hora por dia: com isso, pode-se verificar o comportamento do indicador ao longo do dia e quando ultrapassar os limites toleráveis, outras ações poderão ser tomadas;

- Revisão da meta de devolução diária: assim, ficará mais fácil para gestão controlar o indicador e agir quando necessário;

- Abertura de canal de relacionamento com cliente: por este meio, a empresa poderá estabelecer contato com clientes e fazer pesquisas de satisfação, por exemplo. Ademais, os clientes locais poderão ainda reclamar, fazer elogios e dar sugestões acerca do processo da empresa;

- Acompanhar evolução de devoluções por vendedor: neste caso, o setor de vendas poderá verificar quais colaboradores mais devolvem no mês e com isso estabelecer punições para os que se mantiveram com registros altos de retorno;

- Elaboração e utilização de uma folha de verificação: com esta ferramenta, os itens préestabelecidos no plano de ação poderão ser verificados quanto a situação (realizado, em andamento ou concluído). É importante seu uso para certificar-se de que as atividades foram, realmente, cumpridas, avaliando de forma geral o nível no qual se encontram;

- Aplicação de estudo de correlação, por meio do gráfico de dispersão: com isto, possíveis relações entre causa e efeito de duas variáveis quantitativas podem ser identificadas, ou seja, variáveis estas que podem ser medidas e contadas, como o indicador de devolução em comparação com outra(s).

Como medidas preventivas, indica-se: 
- Revisar os padrões operacionais de devolução: nessa ação, tem-se a oportunidade de verificar inconsistências na avaliação do indicador, assim como no procedimento operacional de devolução;

- Iniciar campanhas educativas acerca de temas ligados a gestão empresarial: com isso, diversos conceitos da administração ficarão mais claros aos funcionários, evitando assim melhor interpretação dos objetivos estratégicos da empresa;

- Envolver os colaboradores com a missão da empresa: fundamental para garantir vantagem competitiva para a empresa, por meio de suas operações.

\section{CONSIDERAÇõES FINAIS}

Devoluções são resultantes, na maioria dos casos, por falha nas operações do processo. Além disso, nenhuma organização deseja tê-las, e reduzi-las é possível, desde que as ferramentas adequadas sejam utilizadas. Para este fim, neste artigo foi possível aplicar as principais ferramentas da qualidade para tentar reduzir os níveis de devoluções em uma empresa de distribuição de produtos alimentícios industrializados.

Tais ferramentas, tratando-se de um conjunto de metodologias é uma forma de melhorar os processos de empresas de diversos setores. Isto posto, a aplicação destas justificou-se pela ampla difusão em ações de gestão, auxiliando na melhoria dos serviços e processos locais. Pôde-se perceber que as ferramentas podem facilitar a definição, mensuração, análise e ainda proposta de soluções e/ou alternativas a resolução de gargalos que influenciam o desempenho da empresa, impactando em diversos aspectos, como financeiro e operacional. Neste estudo, comprova-se o fato de que a partir destas, a gestão tem maior visualização e entendimento do que acontece no seu ambiente, podendo agir de forma mais coerente.

Como visto a partir do Diagrama de Pareto, os motivos "Estabelecimento Fechado", "Cancelamento do pedido", "Cliente sem dinheiro" e "Produto/quantidade errada" representam aproximadamente 80\% dos registros de produtos devolvidos. Assim, com a utilização desta ferramenta, pode-se observar a distribuição dos itens relacionados à devolução, organizando-os do mais frequente ao menos frequente. A sua aplicação neste trabalho foi de suma importância, pois foi utilizado para definir as prioridades a serem tomadas para ação pela empresa. Pode-se citar ainda que houve uma queda de aproximadamente $2 \%$ no indicador de devolução local nos meses seguintes, ou seja, de maio e junho em comparação a abril de 2018.

Como os motivos de maior prioridade foram definidos, o plano de ação foi de extrema importância para listagem e organização das ações necessárias ao cumprimento do objetivo estabelecido por este estudo. Algumas ações ficaram pendentes até a redação do trabalho, apesar da empresa ter se comprometido a executar todas e criar atividades que garantam um retorno menor de produtos na empresa. Além disso, há ações que necessitam de investimento maior, como a implementação de um sistema de roteirização eletrônico e, portanto, exigem planejamento financeiro para execução.

As ferramentas citadas no referencial teórico, algumas não foram aplicadas no período do estudo, como folha de verificação, carta de controle e gráfico de dispersão. Serão empregadas, conforme sugestão, pela gestão em momentos futuros. Assim, cita-se como estudos próximos, a aplicação dessas três ferramentas no contexto aqui abordado, somando-se as demais metodologias das ferramentas comentadas no trabalho. Além disso, como trabalhos futuros, aplicar o estudo desenvolvido em empresas do mesmo segmento.

Como limitação deste trabalho, pode-se citar a restrição quanto ao período, onde não foi possível passar mais tempo observando os resultados devido a necessidade de redação do artigo e o setor no qual o estudo foi estruturado, que foi apenas o de entrega, não abordando situações ou causas de problemas oriundas de outros departamentos da instituição. 


\section{REFERÊNCIAS}

ACOSTA, B.; WEGNER, D.; PADULA, A. D. Logística reversa como mecanismo para redução do impacto ambiental originado pelo lixo informático. Revista Eletrônica de Ciência Administrativa, v. 6, n. 1, p. 1-12. 2008.

AGUS, A. The structural linkage between TQM, product quality performance and business performance: Preliminary empirical study in electronics companies. Singapore Management Review, v. 27, n. 1, p. 87-105. 2005.

ALFALAH, T. F. Total Quality Management Tools: Are they Necessary for Improving Service Quality and Customer Satisfaction? International Review of Management and Marketing, v. 7, n. 3, p.121-125. 2017.

ALZHRANI, K. M.; ALOTIBIE, B. A.; ABDULAZIZ, A. Total Quality Management in Saudi Higher Education. International Journal of Computer Applications, v. 135, n. 4, p. 6-12. 2016.

BROWN, S.; LAMMING, R.; BESSANT, J.; JONES, P. Administração da produção e operações: um enfoque estratégico na manufatura e nos serviços. 2. ed. São Paulo: Campus/Elsevier, 2006.

CARPINETTI, L. C. R. Gestão da qualidade: Conceitos e Técnicas. 2. ed. São Paulo: Atlas, 2012.

CARVALHO, M. M. et al. Gestão da qualidade: teoria e casos. 2. ed. Elsevier: ABEPRO, 2012.

CAUCHICK-MIGUEL, P. A. Estudo de caso na engenharia de produção: estrutura e recomendações para a sua condução. Revista Produção, v. 17, n. 1, p. 216-229, 2007.

COOPER, D. R.; SCHINDLER, P. S. Métodos de pesquisa em administração. São Paulo: Bookman, 2003. 640p.

CORRÊA, H. L.; CORRÊA, C. A. Administração de produção e operações: Manufatura e serviços, uma abordagem estratégica. 3. ed. São Paula: Atlas, 2012.

DALE, B. G.; DEHE, B.; BAMFORD, D. Quality Management Tools. Managing Quality 6e: An Essential Guide and Resource Gateway. New Jersey: John Wiley \& Sons, 2016.

FORBES, L. H.; AHMED S. M. Modern construction: lean project delivery and integrated practices. Boca Raton, Fly: Taylor and Francis Group. 2011.

FUJUN, L.; XIAOLIN, L.; VINCENT, L. Transaction specific investment, relational norms and ERP customer satisfaction: A mediation analysis. Decision Science Journal of Education, v. 11, n. 4, p. 679-711. 2009.

GIL, A. C. Como elaborar projetos de pesquisa. 4. ed. São Paulo: Atlas, 2002.

GUARNIERI, P. et al. WMS - Warehouse Management System: adaptação proposta para o gerenciamento da logística reversa. Produção, v. 16, n. 1, p. 126-139, 2006.

HELLSTEN, U.; KLEFSJÖ, B. TQM as a management system consisting of values, techniques and tools. The TQM Magazine, v. 12, p. 238-244, 2000.

HJORT, K. On Aligning Returns Management with the Ecommerce Strategy to Increase Effectiveness. Gothenburg: Chalmers Reproservice, 2013.

KERZNER, H. Sete Falácias que atrasam a maturidade em gerenciamento de projetos. Mundo Project Management, v. 5, n. 31, p. 8-11 2009.

KUMAR, D.; SOLEIMANI, H.; GOVINDAN, K. Forecasting return products in an integrated forward/reverse supply chain utilizing an ANFIS. International Journal of Applied Mathematics and Computer Science. v. 24, p. 669-682, 2014 
KURUVILA, J. S. et al. Flowchart Plagiarism Detection System: An Image Processing Approach. Procedia Computer Science, v. 115, p. 2-13, 2017.

LACHMAN, L.; LIEBERMAN, H. A.; KANIG, J. L. Teoria e prática na indústria farmacêutica. Lisboa: Fundação Coloutre Gulbekian, 2001.

LEITE, P. R. Logística reversa: meio ambiente e competitividade. São Paulo: Pearson Prentice Hall, 2006.

LEITE, P. R.; BRITO, E. P. Z. Logística reversa de produtos não consumidos: práticas de empresas no Brasil. Revista Eletrônica de Gestão Organizacional, v. 3, n. 3, p. 2014-2229. 2005.

LI, Y.; XU, L.; LI, D. Examining relationships between the return policy, product quality, and pricing strategy in online direct selling. International Journal of Production Economics, v. 144, n. 2, p. 451-460, 2013.

MAGAR, V. M.; SHINDE, V. B. Application of 7 Quality Control (7 QC) Tools for Continuous Improvement of Manufacturing Processes. International Journal of Engineering Research and General Science, v. 2, n. 4, p. 364-371, 2014.

MIOT, H. A. Avaliação da normalidade dos dados em estudos clínicos e experimentais. Vasc Bras., v. 16, n. 2, p. 88-91, 2017.

MOLINA-AZORÍN, J. F. et al. Quality management, environmental management and firm performance: A review of empirical studies and issues of integration. International Journal of Management Reviews, v. 11, p. 197-222, 2009.

MONTGOMERY, D. C. Introduction to Statistical Quality Control. 6th ed. Danvers, MA: John Wiley \& Sons, 2009.

NEYESTANI, B. Seven Basic Tools of Quality Control: The Appropriate Quality Techniques for Solving Quality Problems in the Organizations. Zenodo, 2017.

PÁDUA, E. M. M. Metodologia da pesquisa: abordagem teórico-prática. 10. ed. Campinas: Papirus, 2004.

PIMENTEL, L.; MAJOR, M. J. Quality management and a balanced scorecard as supporting frameworks for a new management model and organisational change. Total Quality Management \& Business Excellence, v. 25, n. 7-8, p. 763-775. 2014.

PINTO, J. K. Project Management: Achieving Competitive Advantage. N.J.: Pearson/Prentice Hall, Upper Saddle River. 2007.

PU, G.; SU, Q.; LIU, Q. A Review of Supply Chain Quality Management: A New Disciplin Direction. Science of Science and management of S.\&T, v. 32, n. 10, p. 70-79, 2011.

REIS, E. A.; REIS, I. A. Análise Descritiva de Dados. Relatório Técnico do Departamento de Estatística da UFMG. 2002.

SANTOS, G. A. et al. A importância dos gráficos de controle para monitorar a qualidade dos processos industriais: Estudo de caso numa indústria metalúrgica. Revista Cadernos do IME - Série Estatística, v. 28, p. 33-46, 2010.

SANTOS, P. V. S. et al. A metodologia design thinking: estratégia gerencial para empreendimentos. Revista Latino-Americana de Inovação e Engenharia de Produção, v. 5, p. 25-43, 2017.

SANTOS, P. V. S. Aplicação do indicador overall equipment effectiveness (oee): um estudo de caso numa retífica e oficina mecânica. Brazilian Journal of Production Engineering, v. 4, n. 3, p. 1-18, 2018. 
SANTOS, P. V. S.; ARAÚJO, M. A. Aplicação de ferramentas lean no setor de logística: um estudo de caso. Revista Gestão em Análise, v. 7, n. 2, p. 168-183, 2018.

SANTOS, P. V. S.; SANTOS, L. D. P. G. Dos.Gestão de indicadores: um estudo de caso no setor de serviços. Brazilian Journal of Production Engineering, v. 4, n. 4, p. 115-133, 2018.

SCHROEDER, R. G.; GOLDSTEIN, S. M.; RUNGTUSANATHAM, M. J. Operations Management in the Supply Chain: Decisions and Cases. New York: McGraw-Hill, 2013.

SHEN, B.; LI, Q. Impacts of Returning Unsold Products in Retail Outsourcing Fashion Supply Chain: A Sustainability Analysis, Sustainability, v. 7, n. 2, p 1-14, 2015.

SIMANOVÁ, L.; GEJDOŠ, P. The Use of Statistical Quality Control Tools to Quality Improving in the Furniture Business. Procedia Economics and Finance, v. 34, p. 276-283, 2015.

TAKALO, S. K. et al. Fuzzy Failure Analysis: A New Approach to Service Quality Analysis in Higher Education Institutions. International Education Studies, v. 6, n. 9, p. 93-106, 2013.

XU, L. et al. Consumer returns policies with endogenous deadline and supply chain coordination. European Journal of Operational Research, v. 242, n. 1, p. 88-99, 2015.

YEUNG, A. C. L.; CHENG, T. C. E; LAI, K. H. An empirical model for managing quality in the electronics Industry. Production and Operations Management, v. 14, n. 2, p. 189-204, 2005.

YIN, R. K. Case study research: design and methods. 3. ed. California: Sage Publications, 2003. 